\title{
SHORT- AND LONG-TERM EFFECTS OF NSAIDS ON THE GASTROINTESTINAL MUCOSA: COMPLEX ANALYSIS OF BENEFITS AND COMPLICATIONS PREVENTION
}

DOI: $10.36740 /$ WLek202104138

\author{
Yana Y. Hnepa, Ivan V. Chopey, Ksenia I. Chubirko, Andriy M. Bratasyuk \\ STATE HIGHER EDUCATIONAL ESTABLISHMENT «UZHHOROD NATIONAL UNIVERSITY», UZHHOROD, UKRAINE
}

\begin{abstract}
The aim: To analyse data from recent studies, dedicated to the use of non-steroidal anti-inflammatory drugs (NSAIDs); to evaluate the best clinical practice in the use of NSAIDs in order to prevent side effects (SEs) in different clinical scenarios; to optimise treatment of patients at risk of NSAIDs-related SEs.

Materials and methods: A comprehensive bibliographic search was performed using the keywords "NSAIDs", "NSAID gastropathy", "NSAID enteropathy", "complications of NSAID therapy", "cardiovascular disease", "cardiovascular risk" in the PubMed, Web of Science, Cochrane Library, Google Academy databases.

Conclusions: NSAID-induced gastrointestinal lesions are a relevant problem of internal medicine, this is due to the fact that the pathogenic mechanisms of this process are still unclear. All the gastrointestinal tract (GIT) related risk factors(RFs) for gastro- and enterocolonopathies associated with the use of NSAIDs should be taken into consideration by physicians of all specialties. The examination and diagnostic of the GIT should be performed regularly to prevent complications. Uncontrolled, long-lasting, unprescribed NSAID usage should draw the attention of doctors, especially in patients with comorbid states.
\end{abstract}

KEY WORDS: non-steroidal anti-inflammatory drugs; NSAID gastropathy; NSAID enteropathy; complications of NSAID therapy; cardiovascular diseases; cardiovascular risk; diclofenac; nimesulide; celecoxib; complications prevention

Wiad Lek. 2021;74(4):1011-1018

\section{INTRODUCTION}

Literature data from many recent studies indicate a significant increase in the incidence of drug-related gastrointestinal tract (GIT) lesions. The topic is of paramount importance in clinical practice [1]. Drugs that have adverse effects on the GIT include antibiotics, aspirin and other anti-platelets drugs, steroids, anti-hypertensives, and other agents. However, most of GIT lesions are associated with the use of non-steroidal anti-inflammatory drugs (NSAIDs), primarily during uncontrolled usage. The duration, frequency and dosage of NSAID prescriptions are quite diverse and physicians across all specialties use them in their daily practice, including therapists, pediatricians, cardiologists, rheumatologists, but most often - general practitioners family medicine. Worldwide, several million people of all ages use NSAIDs daily as prescribed by their doctor [2]. In the United States and developed countries of Europe, $70 \%$ of people older than 65 take NSAIDs at least once a week, and $34 \%$ of them take NSAIDs every day, despite the presence of risk factors, the development of undesirable adverse effects, in the GIT and cardiovascular system (CVS), kidneys and liver [3].Such statistics are mainly explained by the uncontrolled use of these drugs which are sold over-the-counter. Compared to the usage of NSAIDs when prescribed by a doctor, self-prescribed usage occurs 7 times more often. Patients often cannot evaluate the potential interactions that might occur between NSAIDs and other medication, used by the patient to treat other conditions that they might have. Unfortunately, such uncontrolled behavior can considered as an additional RFs for the development of SEs, such as dyspepsia, peptic ulcer formation, bleeding, obstruction, and perforation. NSAIDs can damage the GIT from the esophagus to the rectum, but the proximal section is about 6 times more likely to be affected. The most common and potentially dangerous SE is the so called NSAID-induced gastropathy. This condition manifests with erosive and/or ulcerative lesions of the gastroduodenal tract, which are seen during endoscopy $[4,5]$ in the form of acute multiple gastric erosions and/or ulcers in the absence of local inflammation and histological changes [6].

\section{THE AIM}

The aim was to analyze data from recent studies dedicated to the use of non-steroidal anti-inflammatory drugs (NSAIDs); to evaluate the best clinical practice in the use of NSAIDs in order to prevent side effects (SEs) in different clinical scenarios; to optimize treatment of patients at risk of NSAIDs-related SEs.

\section{MATERIALS AND METHODS}

We identified and reviewed a total of 130 publications published between 2006 and 2021. 


\section{REVIEW AND DISCUSSION}

The increase in the number of cases and severity of intestinal lesions (NSAID-induced enteropathies and colopathy), which are much more difficult to diagnose, is unreasonably overlooked. They account for $40 \%$ of all NSAID-related complications. However, lesions of the GIT mucosa do not occur in all patients taking NSAIDs and are often associated with additional RFs, including: age over 65 year; co morbid states (e.g., cardiovascular or kidney disease); known history GIT lesions and/or GIT complications; the use of high doses of NSAIDs, as well as a combination of two or more NSAIDs; concomitant use of low doses of aspirin; concomitant use of anticoagulants and glucocorticosteroids; Helicobacter pylori (HP) infection.

According to the recommendation of the American College of Gastroenterology (ACG), additional RFs include: taking NSAIDs on an empty stomach (before eating); unhealthy lifestyle, which include smoking, abusive drinking and concomitant cardiovascular, liver and renal diseases [7].

Depending on the presence of several RFs, patients can be stratified for the risk of NSAID-induced GIT lesions into the following risk groups: high risk (recent complications of peptic ulcer disease in the anamnesis, as well as 3 RFs or more); moderate risk (1-2 RFs); low risk (no RFs) [8, 9].

It is recommended to avoid or limit the administration of NSAIDs to subjects with high cardiovascular risk (CVR), on the SCORE scale $(\geq 10 \%)$, especially in the presence of myocardial infarction (MI), acute coronary syndrome, clinically severe coronary heart disease, aortic aneurysm, acute cerebrovascular disease, progressive chronic heart failure (CHF) and other significant cardiovascular comorbidities. Particular caution should be also exercised in patients affected by diabetes mellitus (DM) with end-organ damage, or other RFs, such as chronic kidney disease, especially when the glomerular filtration rate $<30 \mathrm{ml} / \mathrm{min} / 1,73$ $\mathrm{m}^{2}$ (you may have mixed two sentences, revise) [10].The results of a multicenter cross-sectional observational study of patients with osteoarthritis (OA) conducted in Spain showed that among 17,000 patients with OA, $60.3 \%$ of patients had a high gastrointestinal risk, while $32 \%$ had a history of cardiovascular events and uncontrolled arterial hypertension ( $\mathrm{AH}$ ) was recorded in $22.6 \%$. And despite having RFs and contraindications, to more than $50 \%$ of those patients, NSAIDs were prescribed for analgesia [11]. Therefore, the question of safe and effective NSAIDs prescription is still relevant, taking into account all RFs and comorbidities [12].

The basis for adequate administration of this class of drugs is a correct understanding of their action, the mechanism of pathogenesis, and the possible development of GIT complications. NSAIDs have been shown to inhibit prostaglandin (PG) synthesis from arachidonic acid by blocking the enzyme cyclooxygenase (COX) [13]. To date, two isoforms of COX are known: COX-1, located in the cells of various organs, provides their normal function by regulating the production of $\mathrm{PGs}$. The isoform COX-2 is formed when various inflammatory processes occur in the body and provide the synthesis of pro-inflammatory PGs. The anti-inflammatory effect of NSAIDs is associated with the blockade of COX-2, while the SEs on the GIT, kidneys, CVS, liver are mediated by COX-1 inhibition. Recently, data of the new isoform COX-3, have emerged, whose inhibition leads to a decrease in the content of PG E2. Since the latter is found in the cerebral cortex and heart, it provides a central antipyretic and analgesic effects [14]. The basis of the mechanism of action for all NSAIDs is the suppression of both COX-1 and COX-2. The selectivity of NSAIDs is usually considered in the context of the predominant inhibition of COX-2, but the selectivity index of COX-2 is defined as the ratio of inhibitory activity of COX-1 / COX-2. Thus, a lower selectivity index provides more inhibition of COX-2 by NSAIDs. $[6,15]$.

The basis of the pathological changes in the gastrointestinal tract is the disruption of three levels of protection of the mucous membrane (MM): chemical (muco-bicarbonate), cellular, and tissue $[16,17]$. The imbalance between protective and damaging factors underlies ulcerogenesis [18-20]. Several theories aim at explaining the development of GIT pathologies. The first of them is vascular, the main idea of which is ischemia of the gastric wall as a RF of ulceration. According to the peptic theory, pepsin and hydrochloric acid $(\mathrm{HCl})$ are the main damaging factors affecting the gastric mucosa. ("without acid, there is no ulcer") The inflammatory theory identifies the gastritis as a pre-ulcerative condition. Another theory is the so called neurovegetative, according to which pathological changes of the mucous membrane are secondary to dysfunction of the autonomic nervous system. The theory of stress explains the relationship between the formation of ulcers and the production of mucus and its components. In addition to these theories, there is evidence supporting the role of $\mathrm{HP}$ in the pathogenesis of peptic ulcer disease. However, most of these theories mainly explain the development of gastropathy and do not fully cover the pathogenesis of ulcerative lesions of the intestine [21-24].

According to authors Bjarnason I and Takeuchi K, the total number of lesions of the distal intestine on the background of NSAIDs may even exceed the number of cases detected in the upper tract [25-26]. To better understand the effects of NSAIDs, namely ulcerogenesis, several pathogenetic mechanisms need to be considered. According to the first, the increase in the synthesis of leukotrienes and peptide-leukotrienes due to the metabolism of arachidonic acid leads to the development of infiltration of the MM by neutrophils $[6,27]$.

The next mechanism is the activation of lipid oxidation and as a consequence the accumulation of free radicals in tissues. NSAIDs are thought to disrupt the glutathione reduction cycle, which plays an important role in neutralizing free radicals [27-29].

The most studied is the third mechanism of damage to the intestinal MM, which describes the ability of NSAIDs to inhibit the synthesis of nitric oxide (NO), derivatives of which (peroxynitrite) have a local altering effect on MM [30]. 
Table 1. Classification of nonsteroidal anti-inflammatory drugs depending on their ability in therapeutic doses to selectively block the activity of COX-1 and COX-2 (J. Frolich, 1997)

\begin{tabular}{cc}
\hline Group of drugs & Preparations \\
\hline Selective COX-1 inhibitors & Low doses of acetylsalicylic acid \\
\hline Non-selective COX-1 and COX-2 inhibitors & Diclofenac, ibuprofen, piroxicam, indomethacin, naproxenandothers \\
\hline Selective COX-2 inhibitors & Meloxicam, nimesulide \\
\hline Highlyselective (specific) COX-2 inhibitors & Celecoxib, rofecoxib \\
\hline
\end{tabular}

Note: COX iscyclooxygenase.

The mechanisms of development of gastro- and endo-colonopathy differ. After all, enteropathy develops not only as a result of local NSAIDs effect, but also due to their systemic action.Like gastropathy, enteropathies develop because of inhibition of COX-1 and COX-2 activity, which contributes to tissue damage. The basis of NSAIDs-associated enteropathies lies in the cumulative effects on the intestine. The above drugs have the ability to be absorbed in the ileum and by enterohepatic recirculation to be released into the duodenum together with bile, which leads to even greater damage to the mucous membrane. Damage of the intestine occurs due to rupture of the lipid bilayer of epithelial cells by separation of oxidative phosphorylation. Whereas, in the development of NSAIDs gastropathy the critical moment is the adhesion of leukocytes to vascular endothelium [22, 31-34].The issue of changing the quantitative and qualitative composition of the microflora against the background of the use of NSAIDs deserves special attention. Physiologically normal microflora protects the $\mathrm{MM}$ of the intestine from aggressive factors, and longterm use of NSAIDs leads to an increase in the content of gram-negative bacteria and its detrimental effect, which has been confirmed in several studies [22, 31]. Excess bacterial growth in the small intestine can lead to suppression of gastric secretion. Moreover, the use of proton pump inhibitors (PPIs) can worsen the course of NSAID enteropathy $[22,31]$.

Deepening knowledge and accumulation of clinical data on the mechanisms of action of NSAIDs allowed to form a working classification and divide all existing NSAIDs into four groups (Table I).

To understand, which drugs of this groups, should be prescribed, let's look through the most commonly used NSAIDs in Ukraine. We will analise their safety and rates of development of most common complications associated with their use, taking into account the individual sensitivity and comorbidities of the patient.

Acetylsalicylic acid (ASA), as a representative of selective COX-1 inhibitors and a drug that is most often used in clinical practice by physicians all around the world and particularly in Ukraine. In cardiology, ASA is successfully used for secondary prevention of cardiovascular disease (CVD), in the form of mono and combination therapy. The frequency of ASA use, as a representative of NSAIDs, forces us to focus on a wide range of SE in the GIT. The proximal parts of the GIT are most often affected. Studies have shown that the frequency of occurrence of esophageal erosions is around $22 \%$, of ulcers $-0.9 \%$, erosions of the stomach and / or duodenum - $63.1 \%$, and gastric and / or duodenal ulcers - $40 \%[35,36]$.

According to Srinivasan A. and De Cruz P. the ulcerogenic effect of ASA on the intestine may be greater than on the stomach and duodenum. According to current data, the incidence of enteropathy associated with ASA is $50-71 \%$, which is due to continuous lifelong use by cardiac patients [37].

In 1986 I. Bjarnason and co-authors published the results of their study, which studied the effects of NSAIDs, including ASA, ibuprofen, and indomethacin on the intestine. According to the data obtained, even short-term (within 7 days) use of ASA led to a damage of the barrier function of the intestine, and long-term to inflammation of the small intestine.

Additionally, it was found that the formation of ulcers, strictures, bleeding, as well as exacerbation and complications of inflammatory bowel disease, were caused by NSAIDs, in particular ASA $[38,39]$.

According to the World Health Organization, even shortterm use of prophylactic doses of aspirin or a single loading dose can increase the risk of serious GIT complications in the form of subepithelial hemorrhages and erosions. This , in turn, prompted the search for ways to prevent GIT lesions which occur during ASA use. According to the CURE study there may be clear linear relationship between the dose of this drug and the ulcerogenic effect on the GIT. The study results show that the frequency of GIT bleeding directly depends on the dose of ASA: at a dose of less than $100 \mathrm{mg}$ /day, bleeding was observed in $1.2 \%$ of patients; at a dose of from 100 to $200 \mathrm{mg}$ /day - in 1.7\%; and at a dose of ASA over $200 \mathrm{mg} /$ day - in $2.5 \%$ of patients [40].

Therefore, when conducting long-term antiplatelet therapy, the minimum effective dose of ASA is usually recommended.

Nowadays, intestinal-soluble forms of ASA are increasingly used, but they are not completely safe, as they can affect the MM of the small intestine and lead to the development of multiple petechiae, erosions, and ulcers.

The results of the data obtained in the study showed better tolerability of ASA in the enteric form but risk of development to severe GIT complications was not affected [41].

W. Kubler, H. Dariuss howed that the incidence of complications did not depend on the form of ASA, which was accompanied by a higher incidence of GIT bleeding and perforation in patients receiving enteric ASA compared with the traditional form [42]. 
According to Henry D. et al., the pathogenesis of GIT complications is based on the systemic action of the drug. This implies that its enteric form cannot solve the problem of GIT complications development at the moment [43].

Therefore, when deciding on the appointment of ASA, health professionals need to consider the expected benefits of its prescriptions and assess the risk of hemorrhagic complications, in particular from the GIT, because the probability of complications in the first month is three times higher than regular use. If possible, avoid the simultaneous appointment of NSAIDs, glucocorticosteroids, and anticoagulants due to the increased risk of bleeding [44-46].

If NSAIDs are needed concomitantly for analgesic or antipyretic purposes, paracetamol and/or ibuprofen should be preferred. The combination of selective COX-2 inhibitors with ASA is more justified in terms of GIT MM protection, but is not justified in terms of the risk of CVS complications and requires additional gastro-protectants.

The most common analgesic taken by patients of all ages with and without a prescription is ibuprofen. The drug belongs to the group of non-selective inhibitors of COX-1 and COX-2, despite this, ibuprophen showed the lowest risk of NSAID-associated gastropathy, erosions, and ulcers of the stomach and duodenum when compared to other NSAIDs. For ibuprophen the risk was 1.0, for diclofenac it was 2.3 , for aspirin -4.8 , for indomethacin -8.0 , for piroxicam - 9.0, for ketoprofen - 10.3. [47]. Analysis of the data of a cohort of several studies conducted in the United States and Canada showed similar results [48].

Ibuprofen is a relatively safe drug only when used in low, analgesic doses. Increasing the dose of this drug leads to changes in the acidity of gastric juice and the development of NSAIDs-related gastropathy and its complications [49,50].

Diclofenac has long been considered the "gold standard" of non-selective NSAIDs. This drug is one of the most studied and frequently used representatives of this group. It has a well-defined anti-inflammatory and analgesic effect, which is the key to success in patients with degenerative and rheumatic diseases. According to the large MELISSA study involving more than 9,000 patients with osteoarthritis who received meloxicam, $38 \%$ were more likely to refuse treatment because of its ineffectiveness compared with diclofenac ( 80 of 4635 vs. 48 of $4688 ; p<0.01$ ) [51]. This indicates a better clinical efficacy of diclofenac compared to meloxicam. Diclofenac has a lower incidence of gastrointestinal damage compared to ibuprofen and naproxen, which is associated with predominant COX-2 inhibition. The study data was also confirmed by other population-based studies that showed a lower risk of gastrointestinal bleeding with diclofenac and ibuprofen compared with indomethacin, piroxicam, and ketoprofen. However, recent studies have shown that diclofenac is associated with an increased risk of MI, drug-induced hepatitis, and acute liver failure. This confirms the fact that this drug cannot be considered completely safe. All non-selective NSAIDs differ in the degree of adverse event (AE)_on body systems. So it is necessary to use selective COX-2 inhibitors, which show a high safety profile, taking into account RFs for the development GIT lesions and comorbidities [52].

Nowadays, nimesulide is a widely used selective NSAID in Ukraine. Among the advantages of this drug are high bioavailability, rapid analgesia, powerful anti-inflammatory effect, and low frequency of side effects. Easy tissue permeability and its ability to quickly concentrate in the focus of inflammation are associated with its molecule, which has alkaline properties [53]. Nimesulide has low interference with COX-1, so that its use is associated with a lower risk of GIT complications. According to experts of the European Society of Cardiology, such as Schmidt M., Lamberts M., Olsen A.M., the drug occupies an intermediate position between meloxicam and celecoxib [54]. The expressed analgesic, anti-inflammatory action of nimesulide in various dosage forms allows its use for local and systemic inflammation. This has been confirmed by several studies.

Thus, one meta-analysis showed that among 10,608 reports describing $16571 \mathrm{AE}$ due to therapy with various NSAIDs, nimesulide was twice as likely to cause GIT complications than other NSAIDs. The frequency of side effect (SE) in patients who participated in the study, was $10.4 \%$ for nimesulide group for diclofenac $-21.2 \%$, for ketoprofen $-21.7 \%$, for piroxicam - 18.6\% [55].

Another epidemiological study by J. Laporte et al. analyzed 2,813 cases of GIT bleeding with nimesulide and some other NSAIDs. The control group consisted of 7,193 patients without GIT complications. Nimesulide was found to be safer than many other NSAIDs commonly used in Europe: the risk of bleeding was 3.2 for nimesulide, 3.7 for diclofenac, 5.7 for meloxicam, and 7.2 for rofecoxib [56].

Increasingly attention is focused on the hepatotoxicity of NSAIDs, which is quite debatable. Diclofenac sodium and aspirin are toxic to the liver. Later there were data on idiosyncratic lesions of the liver that occurred after taking indomethacin, diclofenac, sulindac. The issue of hepatotoxicity of nimesulide is increasingly discussed in foreign publications [57-59]. Some Italian scientists have conducted studies to assess the hepatotoxicity of various NSAIDs, including nimesulide, but the risk of liver damage in patients taking nimesulide and other NSAIDs, including diclofenac and ibuprofen, was not high [60].

A systematic review of randomized controlled clinical trials analyzed the use of various NSAIDs (naproxen, ibuprofen, diclofenac, celecoxib, rofecoxib, valdecoxib, meloxicam) in patients with osteoarthritis or rheumatoid arthritis. Patients that used diclofenac and rofecoxib were found to have increased level aminotransferases (3.55\% and $1.8 \%$, respectively) compared with placebo $(0.29 \%)$ and other NSAIDs $(0.43 \%)$. The incidence of severe hepatic impairment associated with NSAIDs was very rare and did not exceed $0.04-0.06 \%$ compared with placebo. Drug withdrawal due to hepatotoxic reactions was observed only in patients taking diclofenac (2.17\%), while for other NSAIDs it was not statistically significant. Of the 37,671 hospitalized patients included in the study, only 1 case was associated with hepatotoxic effects of NSAIDs, and of the 51,942 deaths, only 1 case was associated with liver 
damage in the background of NSAID treatment; both patients used naproxen [61]. Diclofenac and rofecoxib had higher aminotransferase elevations than placebo and other NSAIDs studied. None of the NSAIDs studied were found to increase the incidence of toxic liver damage, hospitalizations, or deaths.

According to the Study of Acute Liver Transplant (SALT) - a study of NSAIDs-exposed acute liver failure in European transplant centers, conducted by EMA, which involved 54 transplant centers in Europe, the rate of acute liver failure for the most common NSAIDs in these countries was: 3.3 cases per 1 million for diclofenac, 5.9 for nimesulide and 8.2 for ibuprofen [62]. A similar figure for paracetamol (except in cases of overdose) was 9.8. In two more epidemiological studies conducted in Italy, researchers Mauro Venegoni, Roberto Da Cas, etc., found that the level of all hepatopathies per 100 thousand human years for nimesulide was 35.2, for ketoprofen -25.2 , for diclofenac - 39.2, ibuprofen - 44.6 [63].

A recent systematic review and meta-analysis of 5 observational studies in South Korea showed a toxic effect of nimesulide on the hepatobiliary system [RR 2.21, 95\% CI 1.72-2.83]. According to these studies, the incidence of hepatotoxicity was significantly higher in patients taking nimesulide compared with other NSAIDs. Almost half of the patients receiving nimesulide (45.5\%) required a liver transplant, or died of fulminant liver failure, and a third developed hepatotoxicity within two weeks of taking nimesulide. Therefore, recent studies confirm that nimesulide, being safer for GIT complications, has an increased risk of hepatotoxicity [64].

This issue requires further studies to investigate the effect of drug dose and duration of treatment on liver damage.

This prompted the creation of a new group of NSAID - coxibs. According to the developers, these are specific COX-2 inhibitors. The first of the class of coxibs was celecoxib. The peculiarity of these drugs is their higher affinity for COX-2 rather than COX-1. It is believed that this affinity of coxibs is based on the stereometric structure of molecules, which enables non-competitive blocking of the active center of the isoenzyme [31,34]. At the same level, there is a low dose-dependence in contrast to other NSAIDs. This specificity of COX-2 inhibitors is of interest to practitioners in the context of drug safety. According to studies, long-term use of coxibs in rheumatic diseases, much less often accompanied by the development of gastrointestinal complications [31-34]. However, based on the results of the VIGOR study, cardiovascular safety after the use of coxibs is questionable. Namely, according to the results of 62 studies, which included 94.599 patients, the incidence of MI was higher with selective NSAIDs than non-selective NSAIDs, but a significant increase in risk was observed only when taking rofecoxib. The results of the study showed that the incidence of MI with rofecoxib was higher compared with the group of patients who took naproxen for rheumatoid arthritis (RA). However, at high risk of gastrointestinal enteropathy, the use of naproxen in combination with PPIs still had higher risk of development of GIT complications, compared to coxib monotherapy.
This drug was developed to ensure gastrointestinal safety, prevention of enteropathies, but the increase in cardiovascular events wasn't taken into account.

The randomized MEDAL clinical trial also showed that etoricoxib had a negative effect on blood pressure and had almost the same number of cardiovascular complications as diclofenac [65]. The Committee for Medicinal Products for Human Use (CHMP) and the European Medicines Agency (EMEA) has concluded that the use of selective COX-2 inhibitors is associated with an increased risk of thrombotic heart disease, vascular events, such as heart attack and stroke, as well as decompensation of hypertension $(\mathrm{AH})$ and increased blood pressure. Therefore, according to EMEA experts, COX-2 inhibitors should not be recommended for patients with ischemic heart disease who have suffered a stroke or who have been diagnosed with peripheral artery disease.

However, inconsistent was the fact that the number of serious complications of the proximal and distal GIT on the background of taking etoricoxib and diclofenac was equal: 0.3 and 0.32 and 0.32 and 0.38 per 100 patient-years, respectively $[66,67]$. This fact wasa serious surprise, because the main advantage of coxibs, which distinguishes them from "traditional" NSAIDs, was the reduction of the risk of dangerous complications from the GIT.

An important factor influencing the development of complications from various organs and systems associated with the use of NSAIDs is their timely diagnosis. There is no specific diagnosis, but the possibility of complications from organs and systems, especially in patients at risk, encourages us to perform periodic laboratory tests, actively detectin stances HP infection, prescribe fecal testing for occult blood and calprotectin detection. The main methods of diagnosing lesions of the proximal and distal GIT areesophagogastroduodenoscopy (EGDS) and colonoscopy. If necessary, it is possible to conduct daily esophageal-impedance-pH-monitoring. Examination of the small intestine is less availablebecause video capsule endoscopy is a more technically complex, expensive, and less accessible examination than colonoscopy.

All of the factors stated above compel scientists to focuses on the development of new methods of primary prevention of the most common complications caused by taking non-steroidal anti-inflammatory drugs. In the presence of risks of gastrointestinal complications associated with NSAIDs, selective COX-2 inhibitors are preferred. Additionally, studies have found the best safety profile in both coxibs and selective NSAIDs. To prevent the development of cardiovascular complications with coxib use, it is possible to prescribe non-selective NSAIDs with concomitant use of gastroprotective agents, primarily proton pump inhibitors and/or gastroprotectors.

\section{CONCLUSIONS}

As of today, the problem of NSAID-induced lesions of the GIT remain a relevant issue. This is due to the fact that the pathogenic mechanisms of this process are still 
unclear. All the GIT related risk factors should be taken into consideration by physicians of all specialties during their routine medical practice. The examination of the GIT should be performed regularly to prevent complications. Uncontrolled, long-lasting, unprescribed NSAID usage should draw the attention of doctors, especially in patients with comorbid states.

Diclofenac remains "Golden standard" of unselective NSAIDs and has shown the lowest rate of GIT side effects, when compared to ibuprofen and naproxen.

One of the most prescribed selective NSAID is nimesulide. It has a high safety profile, regarding GIT SEs on par with meloxicam and celecoxib, but has high hepatotoxicity.

The highest safety profile regarding GIT hemorrhage risks was seen in specific COX-2 inhibitors - coxibs. But their use was associated with a higher CV risk, so they should not be recommended to patients with cardiovascular diseases.

Taking all of this into consideration, timely prevention, and diagnosis of NSAID induced damage of the mucous membrane of the GIT, as well as rational and individually tailored NSAID prescription. The search for safer, less damaging to the GIT, with lower CV risk and a nephron- and hepatotoxicity is still ongoing. Until they are developed, if the use of NSAIDs is inevitable, management of patients with comorbid states should include additional measures to prevent complications.

\section{REFERENCES}

1. Parfitt J., Driman D. Pathological effects of drugs on the gastrointestinal tract: are view. HumPathol. 2007; 38(4):527-536. doi: 10.1016/j. humpath.2007.01.014.

2. lee M., Feldman M. The aging stomach: implications for NSAIDgastropathy. Gut. 1997; 41(4):425-426. doi: 10.1136/gut.41.4.425.

3. Morozova T. E., Rykova S. M., Chukina M. A. NPVP-gastropatii u bol'nykh s sochetannoj patologiej serdechno-sosudistoj sistemy I zabolevaniyami sustavov I pozvonochnika. [NSAID gastropathy in patients with comorbid diseases]. Experimental and clinical gastroenterology. 2015;118(6):6470. (In Russian).

4. Novikov V. E., Kryukova N. 0., Krikova A. V. NPVP indutsirovannyye gastropatii ikh profilaktika. [NSAID-induced gastropathies and their prevention]. Reviews on clinical pharmacology and drug therapy. 2008;6(1):26-30. (In Russian).

5. Scarpellini E., Vos R., Blondeau K. et al. The effects of itopride on esophageal motility and lower esophageal sphincter function in man. Aliment. Pharmacol. Ther. 2011;33(1):99-105. doi: 10.1111/j.13652036.2010.04487.x.

6. Maev I.V., Andreev D.N., Dicheva D.T. Gastropatii, inducirovannye nesteroidnymi protivovospalitel'nymi sredstvami: patogeneticheski obuslovlennye podhody k profilaktike i terapii [NSAID-induced Gastropathies: Pathogenetically Substantiated Approaches to Prevention and Therapy]. Pharmateka. 2016;2:49-54. (In Russian).

7. Lanza F., Chan F., Quigley E. Guidelines for Prevention of NSAID-Related Ulcer Complications. Am J Gastroenterol. 2009; 104(3):728-738.

8. Lapina T.L. Gastropatiia, indutsirovannaia nesteroidnymi protivovospalitel'nymi preparatami: puti resheniia problemy. [Nonsteroidal anti-inflammatory drug-induced gastropathy: solutions]. Rus. med. zhurn. 2009;2:54-7. (In Russian).
9. Chan F. The David Y. Graham lecture: use of non-steroidal antiinflammatory drugs in a COX-2 restricted environment. Am J Gastroenterol. 2008;103(1):221-227. doi: 10.1111/j.1572-0241. 2007.01545.x.

10. Karateev A.E., Nasonov E.L., Ivashkin V.T. et al. Racionalnoe-ispolzovanie nesteroidnykh protivovospalitelnykh preparatov. Klinicheskie rekomendacii. [Rational use of non-steroidal anti-inflammatory drugs. Clinical guidelines]. Rheumatology Science and Practice. 2018;56:1-29. (In Russian).

11. Lanas A., Garcia-Tell G., Armada B., Oteo-Alvaro A. Prescription patterns and appropriateness of NSAID therapy according to gastrointestinal risk and cardiovascular history in patients with diagnoses of osteoarthritis. BMC Med. 2011;9(1):38. doi: 10.1186/1741-7015-9-38.

12. Anders H., Vielhauer V. Renal co-morbidity in patients with rheumatic diseases. Arthritis ResTher. 2011;13(3):222-232.

13. Blackler R., Gemici B., Manko A., Wallace J. NSAID-gastroenteropathy: new aspects of pathogenesis and prevention. Curr Opin Pharmacol. 2014;19:11-6. doi:10.1016/j.coph.2014.05.008.

14. Kursov S.V., Nikonov V.V. Tsiklooksigenaza: fiziologicheskie effekty i, deystvie ingibitorov i perspektivy i dalneyshego ispolzovaniya paratsetamola (analiticheskiy obzor). [Cyclooxygenase:physilogical effects, inhibitors action and perspectives of paracetamol usage]. Medicina neotloznyh sostoanij. 2016;5(76):27-35. doi:10.22141/22240586.5.76.2016.76430. (In Russian).

15. Lazebnik L.B., Belova G.V. Sistematiziruyuschaya klassifikatsiya multifokalnyih povrezhdeniy slizistoy obolochki pischevaritelnogo trakta nesteroidnyimi protivovospalitelnyimi NPVP I antitromboticheskimi preparatami «Moskovskaya klassifikatsiya». [Systematizing classification of multifocalle sions of the mucosa of the digestive tract by non-steroidal anti-inflammatory and anti-thrombotic drugs]. Eksperimental'naiai klinicheskaia gastroenterologiia. 2018;(151):19-27. (In Russian).

16. BarinovE., Sulaieva 0., LyakchY. et al. Platelet aggregation measurement for assessment of hemostasis failure mechanisms in patients with gastroduodenal ulcer bleeding. Clin Exp Gastroenterol. 2013;5(6):13948. doi:10.2147/CEG.S45685.

17. Balukova E.V. NPVP-indutsirovannoy gastropatii: ot ponimaniya mehanizmov razvitiya $\mathrm{k}$ razrabotke strategii profilaktiki I lecheniya. [NSAID-induced gastropathy: from understanding of development mechanisms to developing a prevention and treatment strategy]. RMJ. 2017;25(10):697-702. (In Russian).

18. Jarosz M., Szkaradek N., Marona H. et al. Evaluation of anti-inflammatory and ulcerogenic potential of zinc-ibuprofen and zinc-naproxen complexes in rats. Inflammopharmacology. 2017;25(6):653-663. doi:10.1007/s10787-017-0361-0.

19. Lim Y., Lee J., Ku Y. et al. Rescu strategies against non-steroidal antiinflammatory drug-induced gastroduodenal damage. J Gastroenterol Hepatol. 2009;24(7):1169-78. doi:10.1111/j.1440-1746.2009.05929.x.

20. Musumba C., Pritchard D.M., Pirmohamed M. Reviewarticle: cellular and molecular mechanisms of NSAID-induced peptic ulcers. Aliment Pharmacol Ther. 2009; 15;30(6):517-31. doi:10.1111/j.13652036.2009.04086.x.

21. Wallace J. Prostaglandins, NSAIDs, and gastric mucosal protection: why doesn't the stomach digest itself? Physiol Rev. 2008;88(4):1547-65. doi:10.1152/physrev.00004.2008.

22. Balabantseva A.P., Kliaritskaia I.L., Tsapyak T.A. et al. Sovremennyiy podhod k pervichnoy profilaktike NPVP-gastropatiy i enteropatiy. [Modern approaches to primary preventionof NSAID-gastropathy and enteropathy]. Crimean Journal of Internal Disease. 2015;(26):31-38. (In Russian). 
23. Avramenko A.A., Gozhenko A.I., Goidyk V.S. lazvennaiabolezn': ocherkiklinicheskoipatofiziologii [Peptic ulcer disease:essays on clinical pathophysiology]. Odessa; 2008, p.304. (In Russian).

24. Tsimmernan la.S. Gastroenterologiia: rukovodstvo [Gastroenterology: a guide]. Moscow: GEOTAR-Media; 2012, p. 800. (in Russian).

25. Evseev M.A. Protivovospalitelnoe medikamentoznoe povrezhdenie kishechnoy trubki: klinicheskoe znachenie, patogenez, vozmozhnosti profilaktik.[Anti-inflammatory drug-induced injury to the intestinal tube: clinical value, pathogenesis, possibilities of prevention]. Nevrologiya, Neiropsikhiatriya, Psikhosomatika. 2013;(1):79-87. (In Russian).

26. Bjarnason I., Takeuchi K. Intestinal permeability in the pathogenesis of NSAID-induced enteropathy. J Gastroenterol. 2009;44(19):23-29. doi:10.1007/s00535-008-2266-6.

27. Podpletniaia E.A., MamchurV.I. Mechanisms of gastroduodenotoxicity of non-steroidal anti-inflammatory drugs. Journal of the National Academy of Medical Sciences of Ukraine. 2005;(1):47-62. (In Russian).

28. UspenskiyY.P., Baryshnikova N.V., Orlov O.Y. etal. NPVP-assotsiirovannaya patologiya zheludochno-kishechnogo trakta: vyibor preparata, taktika vedeniya patsientov. [NSAID-associatedpathologyofthegas trointestinaltract: choiceofthedrug, tacticsofpatientmanagement]. Spravochnikpoliklinicheskogovracha. 2014;(8):42-47. (In Russian).

29. Lanas Á., Carrera-Lasfuentes P., Arguedas Y. et al. Risk of upper and lower gastrointestinal bleeding in patients taking non-steroidal anti-inflammatory drugs, antiplatelet agents, or anticoagulants. Clin Gastroenterol Hepatol. 2015;13(5):906-12.e2. doi:10.1016/j. cgh.2014.11.007.

30. Sulaieva 0.N., Wallace J. L. Novaya strategiya gastrointestinalnoy protektsii s ispolzovaniem gazoobraznyih mediatorov. [New strategy for gastrointestinal protection based on gaseous mediators application]. Russian Journal of Gastroenterology, Hepatology, Coloproctology. 2016;26(3):17-23. (In Russian).

31. Klyaritskaya I.L., Balabantseva A.P., Fursova V.A. Enteropatii, indutsirovannyie priemom nesteroidnyih protivovospalitelnyih preparatov. [Enteropathies induced by intake of non-steroidal antiinflammatorydrugs]. Crimean Journal of Internal Disease. 2014;(22):3844. (In Russian).

32. Gubska 0.Ju., Kuzminets A.A. NPZP-enterotoksichnist: fokusna problem. [NSAID enterotoxicity: focus on the problem]. Modern gastroenterology. 2018;(103):50-59. doi:10.30978/MG-2018-5-50. (in Ukrainian).

33. Watanabe T., Higuchi K., Kobata A. et al. Non-steroidalanti-inflammatory drug-induced small intestinal damageis Toll-likereceptor 4 dependent. Gut. 2008;57(2):181-7. doi:10.1136/gut.2007.125963.

34. Tkach S., Onischuk L., Balabantseva A. Efficacy and safety of Rebamipide in prevention of NSAID-gastropathy. International Journal of Biomedicine. 2017;7(1):57-59. doi:10.21103/article7(1)_shc1.

35. Collaborative overview of randomised of antiplateled therapy--I:Prevention of death, myocardial infarction and stroke by prolonged antiplateled therapy in various categories of patients. Antiplatelet Trialists' Collaboration. BMJ. 2014;308(6921):81-106. PMCID: PMC2539220

36. Lanas A., Perez-Aisa M., Feu F. et al. A nationwide study of mortality associated with hospital admission due to severe gastrointestinal events and those associated with non steroidalantiinflammatorydrug use. Am. J. Gastroenterol. 2015; 100(8): 1685-93. doi: 10.1111/j.15720241.2005.41833.x.

37. Srinivasan A., DeCruz P. A practical approach to the clinical management of NSAID enteropathy. Scand. J. Gastroenterol. 2017;52(9):941—947. doi: 10.1080/00365521.2017.1335769.
38. Bjarnason I. et al. Effect of non-steroidal anti-inflammatory drugs on the human small intestine. Drugs.1986; 32 (1):35-41.

39. Bjarnason I., Hayllar J. Side effects of non-steroidal anti-inflammatory drugs on the small and large intestinein humans.Gastroenterology. 1993;104(6):1832-1847. doi: 10.1016/0016-5085(93)90667-2.

40. Yusuf S., Zhao F., Mehta S. et al. Effect of clopidogrel in addition to aspirinin patients with acute coronary syndromes without ST elevation. The CURE trial investigators. N Engl J Med 2001; 345(7): 494-502.

41. Korneeva 0.N., Drapkina 0.M. Profilaktika zheludochno kishechnyh oslozhnenij pri prieme anti trombocitarnyh preparatov. [The prevention of gastrointestinal complications in patients taking antiplatelet drugs]. Dokazatel'naya gastroehnterologiya, 2012; 2: 77-81. (In Russian).

42. Kubler W., Darius H. Primary prevention of coronary heart disease with aspirin. J. Kardiol. 2015; 94(3):66-73. doi: 10.1007/500392-005-1309-8.

43. Henry D., Dobson A., Turner C. Variability in the risk of major gastrointestinal complications from non aspirin non-steroidal antiinflammatory drugs. Gastroenerology. 2010; 105(4): 1078-88.

44. ACCF/ACG/AHA 2008 Expert Consensus Document on Reducing the Gastrointestinal Risks of Antiplatelet Therapy and NSAID Use. J Am Coll Cardiol 2008;52(18):1502-17. doi: 10.1016/j.jacc.2008.08.002.

45. Patrono C., Bachmann F., Baigent C. et al. Expert consensus document on the use of antiplatelet agents. The task force on the use of antiplatelet agents in patients with atherosclerotic cardiovascular disease of the European society of cardiology. Eur Heart J. 2004;25(2):166-81.

46. Patrono C., Baigent C., Hirsh J., Roth G. American College of Chest Physicians. Antiplatelet Drugs. American College of Chest Physicians Evidence-Based Clinical Practice Guidelines (8th Edition).Chest 2008; 133(6):199-233.doi: 10.1378/chest.08-0672.

47. Garcia Rodrigues L. Variability in risk of gastrointestinal complications with different non-steroidal anti-inflammatory drugs. Am. J. Med. 1998;104(3):30-34.

48. Singh G., Rosen Ramey D. NSAID induced gastrointestinal complications: the ARAMIS perspective. J. Rheumatology. 1998:25(51):8-16.

49. TrelleS., ReichenbachS., Wandel S. et al. Cardiovascular safety of non-steroidal anti-inflammatory drugs: network meta-analysis. BMJ. 2011;342:1-86.

50. Mattia C., Coluzzi F. COX-2 inhibitors: pharmacological data and adverse effects. Minerva Anesthesiology. 2005; 71(7-8):461-470.

51. Hawkey C., Kahan A., Steinbrück K. et al. Gastrointestinal tolerability of meloxicam compared to diclofenac in osteoarthritis patients. International MELISSA Study Group. Meloxicam Large-scale International Study Safety Assessment. British J. Rheumatol. 1998;37(9): 937-945.

52. Lazebnik L.B., Golovanova E.V., Alekseenko S.A. et al. Rekomendatsii po profilaktike i lecheniyu ezofago-gastro-entero-kolopatiy, indutsirovannyih nesteroidnyimi protivovospalitelnyimi preparatami (NPVP). [Recommendations for the prevention and treatment of esophagogastro-entero-colopathy induced by non-steroidal anti-inflammatory drugs "NSAID"]. Experimental and Clinical Gastroenterology. 2018; 151(3): 4-18. (in Russian).

53. Bunczak-Reeh M., Hargreaves K. Effect of inflammation on the delivery of drugs to dental pulp. J. Endod. 1998;24(12):822-824.

54. Schmidt M., Lamberts M., Olsen A. et al. Cardiovascular safety of nonaspirin non-steroidal anti-inflammatory drugs: review and position paper by the working group for Cardiovascular Pharmacotherapy of the European Society of Cardiology. Eur. Heart J. Cardiovasc. Pharmacother. 2016;2(2):108-118.

55. Conforti A., Leone R., Moretti U. et al. Adverse drug reactions related to the use of NSAIDs with a focus on nimesulide: results of spontaneous reporting from a Northern Italian area. Drug Saf. 2001; 24(14):1081-1090. 
56. Laporte J., Ibanez L., Vidal X. et al. Upper gastrointestinal bleeding associated with the use of NSAIDs: new erversus old eragents. Drug Safety. 2004;27(6):411-20. doi: 10.2165/00002018-200427060-00005.

57. Boelsterli U. Mechanisms of NSAID-induced hepatotoxicity: focus on nimesulid. Drug Saf. 2002;25(9):633-648.

58. Andrade R., Lucena M., Fernandez M. et al. Drug-induced liver injury: an analysis of 461 incidences submitted to the Spanish registry over a 10-year period. Gastroenterology. 2005;129(2):512-521.

59. Traversa G., Bianchi C., Da Cas R. et al. Cohort study of hepatotoxicity associated with nimesulide and other non-steroidal anti-inflammatory drugs. BMJ. 2003; 327(7405):18-22. doi: 10.1136/bmj.327.7405.18.

60. Rostom A., Goldkind L., Laine L. Nonsteroidal anti-inflammatory drugs and hepatictoxicity: a systematic review of randomized controlled trial sin arthritis patients. Clin Gastroenterol Hepatol. 2005;3(5):489-98. doi:10.1016/s1542-3565(04)00777-3.

61. Assessment report for Nimesulide containing medicinal products for systemic use (2012) 20 January 2012, EMA/73856/2012, Procedure number: EMEA/H/A-31/1261 (http://www.ema.europa.eu/).

62. Venegoni M. et al. Effects of the European restrictive actions concerning nimesulide prescription: a simulation study on hepatopathies and gastrointestinal bleedings in Italy. Ann Ist Super Sanita. 2010;46(2): 153-157.

63. Kwon J., Kim S., Yoo H., Euni L. Nimesulide-induced hepatotoxicity: A systematic review and meta-analysis. PLoS One. 2019;14(1):e0209264. doi:10.1371/journal.pone.06209264.

64. Cannon C., Curtis S., FitzGerald G. et al. Cardiovascular outcomes with etoricoxib and diclofenac in patients with osteoarthritis and rheumatoid arthritis in the Multinational Etoricoxib and Diclofenac Arthritis Longterm (MEDAL) programme: a randomised comparison. Lancet. 2006;368(9549): 1771-81.

65. Laine L., Curtis S.P., Cryer B. et al. Assessment of upper gastrointestinal safety of etoricoxib and diclofenac in patients with osteoarthritis and rheumatoid arthritis in the Multinational Etoricoxib and Diclofenac Arthritis Long-term (MEDAL) programme: a randomised comparison. Lancet. 2007; 369(9560):465-73.
66. Laine L., Curtis S., Langman M. et al. Lower gastrointestinal events in a doubleblind trial of the cycl0-oxygenase-2 selective inhibitor etoricoxib and the traditional non steroidal anti-inflammatory drug diclofenac. Gastroenterology. 2008; 135(5):1517-25. doi: 10.1053/j.gastro.2008. 07.067 .

\section{ORCID and contributionship:}

Yana Y. Hnepa: 0000-0002-0276-1466 ${ }^{A, B, D}$

Ivan V. Chopey: 0000-0003-4626-0855 ${ }^{B, E, F}$

Ksenia I. Chubirko: 0000-0002-4379-0538 E,F

Andriy M. Bratasyuk: 0000-0003-4390-2357 E

\section{Conflict of interest:}

The Authors declare no conflict of interest

\section{CORRESPONDING AUTHOR Yana Y. Hnepa \\ Uzhhgorod National University \\ 148 Sobranetska st., 88017 Uzhhgorod, Ukraine \\ tel: +380935488978 \\ e-mail:yana.hnepochka@gmail.com}

Received: 04.11.2020

Accepted: 01.03.2021

A - Work concept and design, B - Data collection and analysis, C - Responsibility for statistical analysis, $\mathbf{D}$-Writing the article, $\mathbf{E}$-Critical review, $\mathbf{F}$ - Final approval of the article 